\title{
La Repubblica napoletana del Novantanove. Memoria e mito.
}

\section{Michèle Benaiteau}

\section{(2) OpenEdition \\ 1 Journals}

\section{Édition électronique}

URL : https://journals.openedition.org/ahrf/1086

DOI : 10.4000/ahrf.1086

ISSN : 1952-403X

Éditeur :

Armand Colin, Société des études robespierristes

\section{Édition imprimée}

Date de publication : 1 mars 2001

Pagination : 152-153

ISSN : 0003-4436

\section{Référence électronique}

Michèle Benaiteau, « La Repubblica napoletana del Novantanove. Memoria e mito. », Annales

historiques de la Révolution française [En ligne], 323 I janvier-mars 2001, mis en ligne le 21 avril 2004 consulté le 24 avril 2022. URL : http://journals.openedition.org/ahrf/1086 ; DOI : https://doi.org/ 10.4000/ahrf.1086

Ce document a été généré automatiquement le 24 avril 2022.

Tous droits réservés 


\title{
La Repubblica napoletana del Novantanove. Memoria e mito.
}

\author{
Michèle Benaiteau
}

\section{RÉFÉRENCE}

La Repubblica napoletana del Novantanove. Memoria e mito, archivio di Stato di Napoli, a cura di Marina Azzinnari, Gaetano Macchiaroli editore, Napoli, 1999,419 p.

1 La culture historique connaît sans doute aujourd'hui une vogue et une diffusion dans le grand public jamais égalées auparavant. Livres, revues, journaux, expositions répandent les résultats des recherches savantes soit dans leur forme première, soit à travers une vulgarisation. Les célébrations officielles ajoutent aussi leur concours...À l'occasion du bicentenaire de la Révolution française, les historiens italiens lancèrent le Comité 1799 chargé de célébrer entre autre l'anniversaire de la République napolitaine (21 janvier 1799 - 21 juin 1799), toute dernière parmi les républiques nées de la fièvre révolutionnaire qui enflamma l'Amérique et l'Europe à la fin du xviIIesiècle. Cet événement, tombé dans les oubliettes de l'histoire nationale italienne connue par l'école, vient donc de bénéficier d'une année de manifestations culturelles très variées en Italie, et en particulier dans le Mezzogiorno, où cette République s'instaura à l'occasion de l'échec militaire du roi de Naples contre la République romaine soutenue par les armes françaises.

2 Le volume présenté ici a été publié par les Archives d'État de Naples en fonction de l'exposition sur la République de 1799 mise sur pied par cet organisme (13 décembre 1999 - 30 avril 2000), sous la responsabilité de Marina Azzinnari. Ce volume, conçu en partie comme catalogue de 240 pièces exposées au siège des Archives (200) et dans les locaux de la Bibliothèque nationale de Naples (40), a été enrichi de 198 illustrations concernant surtout l'iconographie relative à la République, de trois articles où les réalisateurs de l'exposition expriment les raisons de leurs choix, et enfin de sept articles écrits par des historiens, spécialistes de la question à divers titres. 
3 Les organisateurs (M.Azinnari, S.Attanasio, M.Vergiari) ont donc opté clairement pour la culture historique professionnelle quant au contenu, confiant la mission de vulgarisation à la forme de l'exposition construite sur un parcours didactique, attrayant par l'iconographie et l'existence d'une documentation audiovisuelle. Il s'agit toutefois d'une pédagogie réservée à un public familiarisé avec la pratique historienne, enseignants ou simples amateurs mais déjà rompus à la lecture d'ouvrages d'histoire érudite.

4 Le thème du volume, «Mémoire et mythe», dérive tout naturellement de l'opération entreprise: faire connaître un événement oublié et suivre les avatars d'un mythe délaissé, ce qui favorise une approche critique de l'histoire en général. La République napolitaine fut défaite par les armes royalistes et le gouvernement restauré (le roi, Ferdinand de Bourbon, et la reine, Marie-Caroline de Hasbourg, sœur de Marie-Antoinette), non content d'exercer une sanguinaire répression, mit de l'acharnement à effacer la mémoire de la république, détruisant les documents qui en prouvaient l'existence... (M. Azzinnari, pp.177-184). Le terrain était bien déblayé pour l'épanouissement d'une histoire fortement conditionnée par l'esprit de parti du côté des témoins contemporains, puis par la philosophie politique du côté des générations successives. Aujourd'hui, le travail des archivistes nous restitue ce qu'ils ont patiemment retrouvé des actes et des documents originaux, tandis que les historiens nous expliquent comment, sous le masque du témoignage ou de l'érudition, ce qui s'offre comme mémoire n'est souvent que mythe sophistiqué...

5 En premier lieu Giuseppe Galasso («Trois ans de républiques jacobines en Italie», pp. 25-38) fait l'histoire du terme "giacobino» en italien, appliqué injurieusement tout d'abord par les contre-révolutionnaires aux fauteurs des républiques italiennes, établies (1796-1799) sous l'égide des armes françaises quand, en France, les jacobins étaient exclus du pouvoir et leur nom officiellement honni. La reprise du terme par l'historiographie successive est donc critiquable mais renvoie à une certaine philosophie politique du Risorgimento qui aimait souligner ainsi une rupture entre l'idée jacobine du peuple «des droits de l'homme et du citoyen», et celle plus proprement italienne du peuple «du droit national». Simultanément se développait l'idée d'une révolution passive imposée par la force des armes par quelques républicains fanatiques ou ingénus dont l'enthousiasme idéaliste n'aurait éveillé aucun écho dans le reste de la société.

6 Anna Maria Rao fait plus précisément le point sur le mythe et l'histoire de la république napolitaine (pp.39-66). Partant de la fortune rencontrée par ce sujet comme matière d'anectodes romanesques ou bien comme panégyrique de martyrs d'une cause idéalement rattachée à la philosophie politique de certains auteurs (par exemple B.Croce), elle confronte ces approches avec d'autres interprétations apparues récemment sur la base d'une méthode différente de travail. Il suffit de replacer la République napolitaine dans le contexte politique européen qui la génère pour considérer différemment les protagonistes et leur œuvre. Et, comme les travaux récents le démontrent, en lançant systématiquement la recherche sur diverses pistes, beaucoup de faits nouveaux ont émergé, obligeant l'historien à nuancer toute conclusion schématique et tout jugement tranché.

7 Par exemple, Maria Graziay Maiorini (pp.67-90), en présentant les résultats de travaux sur le détail des manifestations républicaines et des mouvements populaires de réaction des provinces ${ }^{1}$, déplace inévitablement l'attention du lecteur vers la difficulté 
de synthétiser les faits connus sous la forme d'un jugement politique. Renata De Lorenzo (pp.91-110) évoque l'histoire de la République napolitaine dans la pensée politique italienne du xIxesiècle, qui après 1821 , en a fait un mythe négatif, une erreur à ne pas renouveler. Plus mythiques encore apparaissent les portraits des protagonistes, en particulier les femmes Eleonora Fonseca Pimentel ou Luisa Sanfelice, dont Maria Rosaria Pelizzari (pp.111-136) suit le développement légendaire depuis les témoignages contemporains jusqu'à l'inspiration artistique récente. Almerinda Di Benedetto (pp. 137-160) analyse un phénomène semblable en se penchant sur l'iconographie de la république. Enfin A. Buccaro nous permet de situer les informations reçues sur les faits déroulés à Naples dans un contexte urbain concret, celui d'une "capitale européenne: architecture et bases de la ville bourgeoise» (pp.161-176). Par le contraste entre la nudité des documents du catalogue et la complexité des discours historiographiques, se trouve démontée sous nos yeux la machine trompe-l'œil des faits historiques, qui, loin de parler tout seuls, reçoivent toujours leur inspiration de souffleurs plus ou moins bien cachés.

\section{NOTES}

1.Les «sanfedisti» ralliés au cardinal Ruffo qui reconquirent le territoire sur les jacobins italiens et

l’armée française. 